\title{
Written, personalised feedback in addition to a standard intervention increased smoking cessation
}

Becoña E, Vázquez FL. Effectiveness of personalized written feedback through a mail intervention for smoking cessation: a randomized-controlled trial in Spanish smokers.J Consult Clin Psychol 2001 Feb;69:33-40.

QUESTION: In participants with a self-assessed desire to stop smoking, is a standard intervention (SI) plus written, personalised feedback more effective than the SI alone?

\section{Design}

12 month randomised (unclear allocation concealment*), blinded (outcome assessors)*, controlled trial.

\section{Setting}

Galicia, Spain.

\section{Participants}

300 participants (mean age 37 y, $52 \%$ men, $64 \%$ married, $82 \%$ with $\geqslant$ high school education) who lived in Galicia for the duration of the study and smoked $<10$ cigarettes/ day. Exclusion criteria included current nicotine replacement or other pharmacotherapy or psychotherapy to stop smoking. Follow up was $95 \%$.

\section{Intervention}

100 participants were assigned to SI alone, 100 to feedback, and 100 to a control group. The SI and feedback groups received 1 mailing/week for 6 weeks, each containing a pamphlet with new strategies to stop smoking, a personalised letter of introduction with task instructions for the week, and self monitoring and evaluation forms to be returned at the end of each week. The feedback group in addition received 2 one page mailings between the $3^{\text {rd }}$ and $4^{\text {th }}$, and the $5^{\text {th }}$ and $6^{\text {th }}$ week, with computer generated feedback determined by the responses in their self monitoring and evaluation forms.

\section{Main outcome measures}

Non-smoking rate (not smoking for $7 \mathrm{~d}$ before the 3 and 6 mo follow up, and not smoking for $30 \mathrm{~d}$ before the 12 mo follow up) and continuous non-smoking rate (not smoking even a puff since initially stopping) were based on self report and having $<9$ parts per million carbon monoxide in expired air.

\section{Main results}

Participants receiving feedback had a higher cessation rate at the end of treatment; a higher non-smoking rate at 3,6 , and 12 months; and a higher continuous nonsmoking rate at 3 and 12 months than those receiving SI alone (table). No participants in the control group had stopped smoking at the end of treatment or at 12 months.

\section{Conclusion}

In participants with a self-assessed desire to stop smoking, a standard intervention plus written, personalised feedback was more effective than a standard intervention alone.

*See glossary.
Source of funding: no external funding.

For correspondence: Dr E Becoña,

University of Santiago de Compostela, Faculty of Psychology,

Department of Clinical Psychology and

Psychobiology, Campus Universitario Sur,

15706 Santiago de Compostela, Galicia Spain.Fax +34981 521581 .

Written, personalised feedback plus standard intervention v standard intervention alone (control) for smoking cessation $\dagger$

\begin{tabular}{|c|c|c|c|c|}
\hline Outcomes & Feedback & Control & $\mathrm{RBI}(95 \% \mathrm{Cl})$ & NNT (Cl) \\
\hline Non-smoking at 3 months & $37 \%$ & $22 \%$ & $68 \%$ (8 to 164$)$ & 7 (4 to 43$)$ \\
\hline Non-smoking at 12 months & $27 \%$ & $13 \%$ & $108 \%$ (16 to 278$)$ & $8(4$ to 34$)$ \\
\hline Continuous non-smoking at 3 months & $36 \%$ & $21 \%$ & $71 \%(9$ to 173$)$ & $7(4$ to 41$)$ \\
\hline
\end{tabular}

†Abbreviations defined in glossary; RBI, NNT, and $\mathrm{Cl}$ calculated from data in article.

\section{COMMENTARY}

Reducing the use of tobacco products, especially cigarettes, remains one of our most important preventive health goals. New cost effective innovations that can effectively reduce smoking prevalence are most welcome. In this study, Becoña and Vázquez report a high rate of success using a relatively "low tech" and low cost approach to counselling smokers. The high rates of success in both the feedback group and the SI group were surprising. It is even more surprising to see a $0 \%$ cessation rate in the control group, a finding not seen in most other smoking cessation trials. As it appears that a highly motivated group of subjects were recruited for the study, the $0 \%$ quit rate in the control group raises several questions. Was there something unusual about the control group or their instructions that would limit or defer the naturally occurring rate of quitting? Are smokers in Galicia really that different from those in other populations? The authors' explanations are reasonable, but may not fully explain the findings. Their findings contrast with those of a general population survey in the UK which found that $31 \%$ of smokers attempt to quit with $29 \%$ of those being successful (overall quit rate of $9 \%$ after 3 mo of follow up). ${ }^{1}$

In a recently published study from the UK, Lennox et al applied a similar, though not as complete, approach to more than 2500 smokers in a general practice population in Scotland. They showed a modest increase in validated 6 month cessation rates of $4.4 \%$ compared with $2.6 \%$. Tailoring the message to respond to patient feedback had no added effect. ${ }^{2}$ Other studies of telephone counselling of smokers motivated to quit have shown mixed results. ${ }^{34}$

The next step is to take the same approach and apply it to a clinical area where patient motivation may not be as high, and with an unselected group of smokers from the general population. We need to continue to search for flexible, low cost, and widely available counselling approaches that can encourage a greater proportion of smokers to attempt-and succeed-to quit.

1 West R, McEwen A, Bolling K, et al. Smoking cessation and smoking patterns in the general population: a 1-year follow-up. Addiction 2001;96:891-902.

2 Lennox AS, Osman LM, Reiter E, et al. Cost effectiveness of computer tailored and non-tailored smoking cessation letters in general practise: a randomised controlled trial. BMJ 2001;322:1396.

3 Borland R, Segan CJ, Livingston PM, et al. The effectiveness of callback counseling for smoking cessation: a randomized trial. Addiction 2001;96:881-9.

4 Zhu SH, Stretch V, Balabanis M, et al. Telephone counseling for smoking cessation: effects of single-session and multiple-session interventions. J Consult Clin Psychol 1996;64:202-11. 